\title{
A UTOPIA DA TRADUÇÃO EM AUSTERLITZ: UMA OBRA ENTRE TRÊS LINGUAGENS
}

\author{
Isabel Florêncio Pape* \\ Universidade de Hamburgo
}

\begin{abstract}
Resumo: Este texto discute a relação entre os regimes visual e verbal na obra Austerlitz de W. G. Sebald (1944-2001) e propõe uma comparação entre a obra alemã e as traduções portuguesa e brasileira, analisando os deslocamentos de sentido que surgem quando, nas traduções, a disposição das fotografias é alterada dentro do texto. Ao modo de Mieke Bal, o espaço de interação entre o legível e o visível é entendido como o espaço de entrecruzamento, suplementaridade e desdobramento de sentidos. Assim não há em Austerlitz uma relação de autonomia entre imagem e texto, mas sim de interdependência mútua, na qual a vitalidade semio-estética da obra se ancora. A comparação analítica de três passagens da obra pretende mostrar que, numa tradução, na qual estão envolvidos diferentes regimes de signos, certas mudanças na forma refletem não apenas em diferenças plásticas, mas também em mudanças simbólicas e conceituais. Se de um lado as análises pretendem elucidar a riqueza discursiva que se esconde na interface imagem-texto dentro da obra de Sebald, de outro revelam também quão complexa e utópica é a tarefa tradutora quando esta se confronta não apenas com as distâncias entre as línguas, mas também entre as linguagens.
\end{abstract}

Palavras-chave: Sebald. Tradução. Fotografia. Semio-estético. Imagem-texto.

* Formação em Belas Artes, EBA/Universidade Federal de Minas Gerais. Mestrado em Comunicação Social, FAFICH/Universidade Federal de Minas Gerais. Doutorado em Literatura Comparada e Estudos Semióticos, FALE/Universidade Federal de Minas Gerais. Doutorado Sanduíche na Humboldt Universität em Berlim, Programa CAPES/DAAD. Pesquisadora visitante no Graduierten Kollege Mediale Historiographie, Bauhaus-Universität em Weimar. Professora contratada do Instituto de Estudos Latinos Americanos na Universidade de Hamburgo, Alemanha. E-mail: isabelflorencio@yahoo.com.br 


\title{
THE UTOPIA OF THE TRANSLATION WITHIN AUSTER- LITZ: ONE WORK BETWEEN THREE LANGUAGES
}

\begin{abstract}
This paper discusses the relationship between verbal and visual systems in the work Austerlitz of W. G. Sebald (1944-2001) and considers the comparison between the German version and the translations from Portugal and Brazil, analyzing the shifts of meaning that arise when, in translation, the arrangement of the photographs within the text is changed. The analytical comparison of three passages from the work shows that in a translation that involves different systems of signs, certain changes in the plastic disposition reflect differences in symbolic and conceptual changes. By Mieke Bal's mode, space interaction between the legible and visible is understood as the space of intersection, and deployment of supplementarity senses. So there is at Austerlitz a relationship between self image and text, but of mutual interdependence in which the semio-aesthetics vitality of the work finds support. On the one side the analyzes aim to elucidate the discursive richness that lurks in the image-interface text within the work of Sebald, and on the other, also reveal how complex and utopian is the translation when it is confronted not only with the distances between the verbal language, but also between the verbal and visual languages.
\end{abstract}

Keywords: Sebald. Translation. Photography. Semio-aesthetic. Image-text.

\section{Introdução}

A obra Austerlitz de W. G. Sebald (1944-2001) foi publicada duas vezes na Alemanha. A primeira pela Hanser Verlag, em 2001 (Fig. 1), e a segunda pela Editora Fischer, em 2003 (Fig. 2). A comparação entre ambas revela que, mesmo tendo formatos ligeiramente distintos, a segunda versão seguiu, rigorosamente, o mesmo layout da primeira, reproduzindo a disposição das sentenças e até mesmo as divisões silábicas. Assim nas duas versões é mantida a mesma posição das fotografias em relação ao texto. A tradução portuguesa foi editada em 2004 pela Editora Teorema / Lisboa (Fig. 3), e no Brasil foi publicada pela Martins Fontes em 2008 (fig. 4).

Cad. Trad., Florianópolis, $n^{0}$ especial, p. 14-36, jul./dez. 2014 


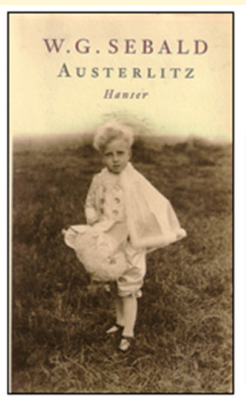

Hanser 2001

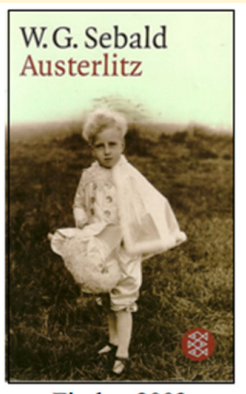

Fischer 2003
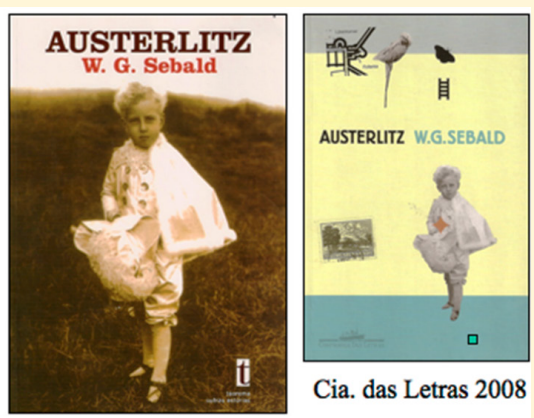

Cia. das Letras 2008

Teorema 2004

Figuras 1- 4: Capas das duas versões alemãs, portuguesa e brasileira, respectivamente.

O interesse na análise comparada da obra Austerlitz surgiu em 2006 diante de um certo desconforto percebido durante a leitura da versão portuguesa. A falta de domínio da língua alemã naquela época me motivou a procurar primeiro a tradução portuguesa, pensando assim, que, superada parcialmente a barreira de ordem linguística, seria possível acessar o discurso de Sebald. Mas para minha surpresa, mesmo sem ter lido a versão alemã, me confrontei com um certo estranhamento na construção discursiva, que não era gerado por diferenças de ordem semântica, mas sim pelo modo como as fotografias dialogavam com o texto dentro do novo layout proposto por esta versão.

Recentemente retomei a leitura da versão alemã e ao compará-la com as versões portuguesa e brasileira, constatei que o desconforto percebido há alguns anos, refletia, na verdade, a percepção de que havia um descompasso no diálogo entre o regime visual e verbal e que implicava em transformações significativas no campo simbólico e discursivo da obra.

Tendo como pressuposto que certas mudanças na forma - (tais como qualidade de impressão, formato, diagramação/layout) - refletem não apenas em diferenças plásticas, mas também em diferenças simbólicas e conceituais, o propósito deste texto é focalizar 
e analisar as diferenças discursivas, que surgem nas traduções, quando, um novo layout, modifica a interação imagem-texto ${ }^{1}$.

De certo modo, pode-se argumentar que a mudança na disposição das imagens em relação ao texto pode passar despercebida ou também ser considerada irrelevante para a leitura de um romance, uma vez que as páginas de um livro podem ser viradas ao sabor e ritmo dados pelo leitor. Contrariando esta perspectiva simplista e seguindo os propósitos da minha pesquisa no campo da intermidialidade, segundo as perspectivas de Mitchell e Bal, decidi analisar crítica e pontualmente o diálogo e o movimento narrativo construído na interação imagem-texto em três passagens distintas desta obra. (MITCHELL, 1995. BAL, 1991) A comparação entre as três versões expõe assim mais uma faceta da complexa tarefa tradutora (BENJAMIN, 2001), quando esta atua no campo de interseção entre regimes de signos distintos.

\section{Imagem-texto: a vitalidade semio-estética em Austerlitz}

W. G. Sebald é conhecido pelo modo como a sua narrativa está ancorada na utilização de imagens, especialmente fotografias em preto e branco, feitas por ele ou apropriadas de outros. A sua estratégia de construção discursiva é delineada por três caminhos distintos, conforme este declara em entrevista concedida a Scholz, em 1997. A primeira consiste em delinear histórias vindas das próprias imagens. A segunda de caminhar pela imagem e descrevê-las através de uma narração, que é uma estratégia ecfrasística clássica. A terceira consiste em implantar as imagens em uma passagem do texto, como se tivesse sido tomada por algum personagem (SCHOLZ, 2007, p.104).

Esta declaração mostra como a inspiração e a linguagem de Sebald não apenas se respaldam nas fotografias, mas emanam delas para se transformar em texto. Assim fica evidente que as imagens não cumprem um papel secundário na narrativa. Elas não atuam como coadjuvantes, mas, ao contrário, possuem uma relevância 
central no discurso. Sendo assim, a posição das imagens desempenha um papel estético e semântico dentro da obra, uma vez que não é inserida no texto como ilustração, mas é pensada segundo uma proposta de interação e remissão mútua de sentidos (BAL, 1991).

No arquivo de literatura em Marbach, Alemanha, onde estão os seus rascunhos e coleções de recortes e fotografias, pode-se constatar o nível de minúcias e preocupação com que Sebald investiga acerca da melhor posição no texto para a inserção das imagens. Colando e recolando insistentemente fragmentos, o autor realiza esta investigação como quem busca a potencialização máxima do elo de contato semântico, simbólico e plástico entre os dois regimes.

Parte da sua estratégia discursiva consiste em inserir o signo visual, sistematicamente, após a primeira referência verbal à imagem ou à citação de um dos elementos que compõem a imagem. Esse recurso revela não apenas uma preocupação formal, que ancora concreta e fisicamente o regime visual e verbal ao longo de todo o livro, mas também sinaliza que esta correspondência é parte constituinte da arquitetura narrativa (Figs. 5, 8, 11).

Em Sebald a fotografia não desempenha apenas o papel de testemunho ou de documentação. Embora as fotografias isoladas tenham predominantemente um caráter indicial e descritivo, e sejam utilizadas como rastro de memória, percebe-se que, através do texto, as fotografias ganham uma camada simbólica, que, sem encobrir, se superpõe à sua camada indicial e figurativa. Mais que atestar e descrever fatos, a fotografia ancora o discurso verbal em diferentes níveis, permitindo construir o fio narrativo e imantando-o de uma carga estética e simbólica. Esta relação não ocorre de forma linear e unidirecional, mas ao contrário, dialógica, e se desdobra elipticamente à medida que signos do texto imantam de sentido certos fragmentos visuais da imagem, e vice-versa (PATT, 2007). Através desta trama signica o autor cria uma certa trajetória de leitura, na qual imagemtexto se completam e se modificam, mútua e reciprocamente.

A obra joga com a memória em muitos níveis distintos, tendo dentre eles, claro, a fotografia como detentora clássica deste recurso de rememoração. Entrecortando lembranças de períodos 
de vida diversos, mesclando passagens da história da civilização com descrição de objetos de arte e arquitetura, locais de viagens, fotografias, lembranças e digressões, a obra narra o percurso risomático e elíptico de Austerlitz na busca do seu passado. A trilha elíptica que organiza o discurso metaforiza não apenas o trabalho de perlaboração do protagonista em busca da sua identidade, mas também reflete a estratégia discursiva de Sebald, na qual a flutuação de sentidos entre imagem-texto compõe a vitalidade poética e conceitual da narrativa (BAL, 1997).

Assim, a leitura de Austerlitz, que foi, de antemão, motivada pelo meu interesse teórico na relação imagem-texto, me fez confrontar com a questão de ordem semio-estética que envolve a tradução de uma obra calcada na interação entre dois regimes de signos. Com este termo pretendo incluir os aspectos plásticos e simbólicos que constituem o vitalismo entre os dois regimes na obra de Sebald. Compreendo que este conceito, além de contemplar os componentes conceituais e plásticos, que surgem da interface entre os regimes de signo na narrativa sebaldiana, também serve como ponte para se superar a relação dicotômica entre o regime visual e o verbal, sugerindo que os dois regimes se tocam, interagem e se modificam mutuamente ${ }^{2}$.

Segundo a perspectiva aqui adotada, não há em Austerlitz uma relação de autonomia entre imagem e texto, mas sim de interdependência mútua (BAL, 1991). Portanto a fotografia não cumpre uma função meramente ilustrativa. A vitalidade discursiva de Austerlitz sobrevive da interação imagem-texto e quando se modifica a disposição das imagens no corpo do texto, haverá sempre uma interferência no diálogo entre os dois regimes, que modifica o aspecto semio-estético da obra. Em certo sentido, e mantidas as devidas proporções, seria como se numa obra de arte que mescla signos verbais e plásticos como, por exemplo, em Duane Michals, Jasper Johns, Barbara Kruger, a parte legível da obra fosse separada da porção pictórica e colocada ao seu lado. Esta relação não modificaria o conteúdo objetivo de cada linguagem em si, mas alteraria significativamente o diálogo entre-linguagens. 
A interseção destes dois regimes produzem certas afecções, que funcionam como um terceiro campo de linguagem, nem visual, nem verbal, mas semio-estético.

Os três casos analisados mostram formas distintas de "descompasso" na interface imagem-texto além de representarem três modos diferentes de apropriação de imagem dentro do discurso sebaldiano.

O primeiro tipo é baseado numa relação simbólica do texto com a imagem, no qual se percebe um deslocamento do caráter indicial da fotografia em direção ao nível de caráter mais simbólico. O segundo está baseado numa relação de justaposição de signos, onde se dá um ancoramento físico e conceitual entre os dois regimes. O terceiro é caracterizado por uma relação ecfrasística, na qual o texto, ao descrever a fotografia, amplia a percepção de certos detalhes visuais e que, retorna ao sentido do texto, modificando-o.

De modo a organizar visualmente a leitura aqui proposta e com o objetivo de mostrar como se percebe a conexão entre certa passagem do texto com a fotografia, foram reproduzidas as páginas dos livros (Figs. 5, 13B). Através de setas e grifos sobre as páginas procurei indicar o percurso de leitura e as partes das sentenças que atuam mais pontualmente como elementos conectores na interface imagem-texto. Para melhor visualização das versões, cada uma delas (alemã, portuguesa, brasileira) está sinalizada com a bandeira do país de origem no canto inferior esquerdo. Ao me referir às cenas da obra, tomarei como referência a versão alemã editada pela Hanser, de modo que a paginação, quando citada, será feita de acordo com esta versão. Para maior fluidez de leitura será evitada a citação contínua da paginação a cada referência feita, uma vez que na identificação das imagens já constam os números das páginas.

A primeira análise se detém numa passagem do texto onde o narrador descreve uma visita feita, com Austerlitz, ao observatório astronômico de Greenwich (Figs.5, 7B). A cena se desenrola numa sala onde estão contidos aparelhos de medição, "cronômetros e relógios expostos em caixas de vidro". A imagem de uma 
vitrine com dois cronômetros é inserida logo após esta sentença da página, expondo, mais uma vez, o modo típico e sistemático com que Sebald situa as fotografias em relação ao texto (Fig. 5). Segue-se então o relato de uma longa divagação de Austerlitz acerca da relatividade e da noção arbitrária que organiza os sistemas de medição do tempo. O protagonista reflete sobre a ação inexorável do tempo sobre as coisas e sobre nós mesmos, que paradoxalmente, se de um lado, é o que permite construir a memória, é de outro, também aquilo que nos afasta, mais e mais, da nossa experiência ${ }^{3}$.

De início a fotografia parece apenas ilustrar de forma ingênua uma das vitrines vistas no observatório. Mas com o desenrolar da digressão acerca do tempo, que sugere, de forma poética, a angústia do protagonista diante da tentativa inútil de recuperar a sua história passada, a fotografia deixa de desempenhar apenas um papel descritivo e factual ${ }^{4}$. Neste sentido, a digressão funciona como um fio invisível que, imantando a fotografia de outros sentidos, permite que esta se desloque para um nível simbólico e passe a representar não apenas o seu objeto imediato, mas outros aspectos subjetivos tais como a relatividade do tempo e a impotência do sujeito diante do tempo passado.

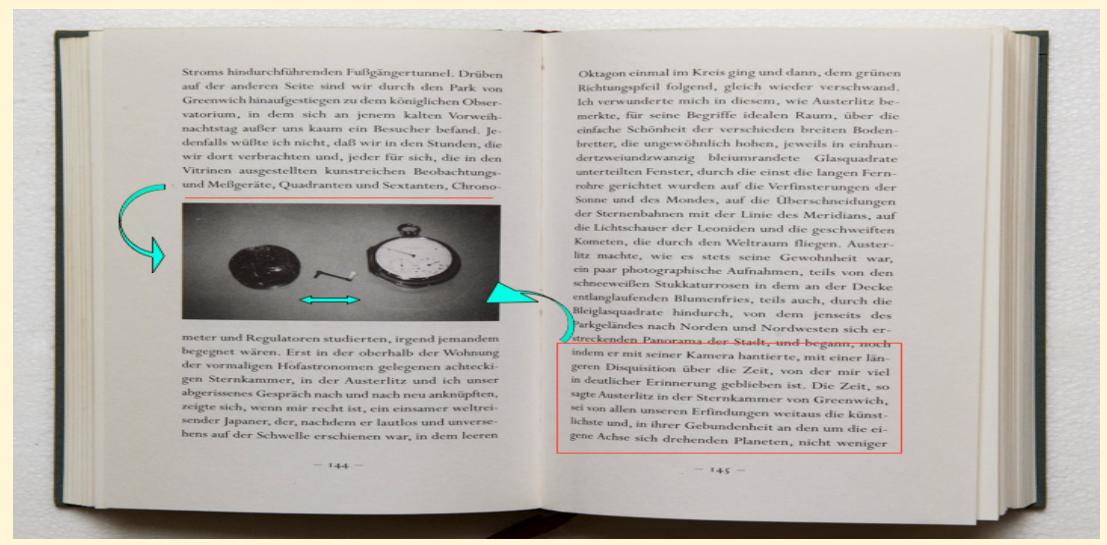

Fig. 5 - Páginas 144-145

Cad. Trad., Florianópolis, $n^{0}$ especial, p. 14-36, jul./dez. 2014 


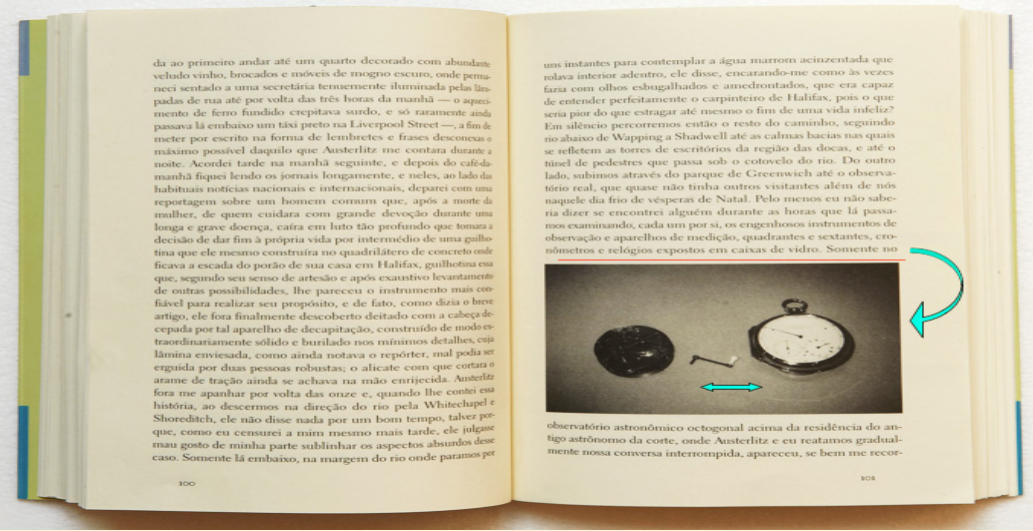

Fig. 6- Páginas 100-101

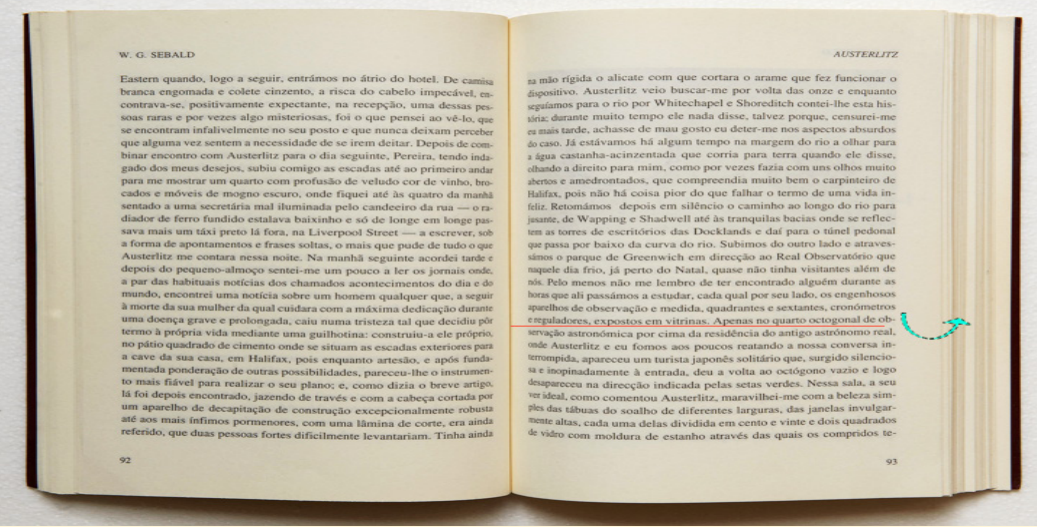

Fig.7A - Páginas 92-93 


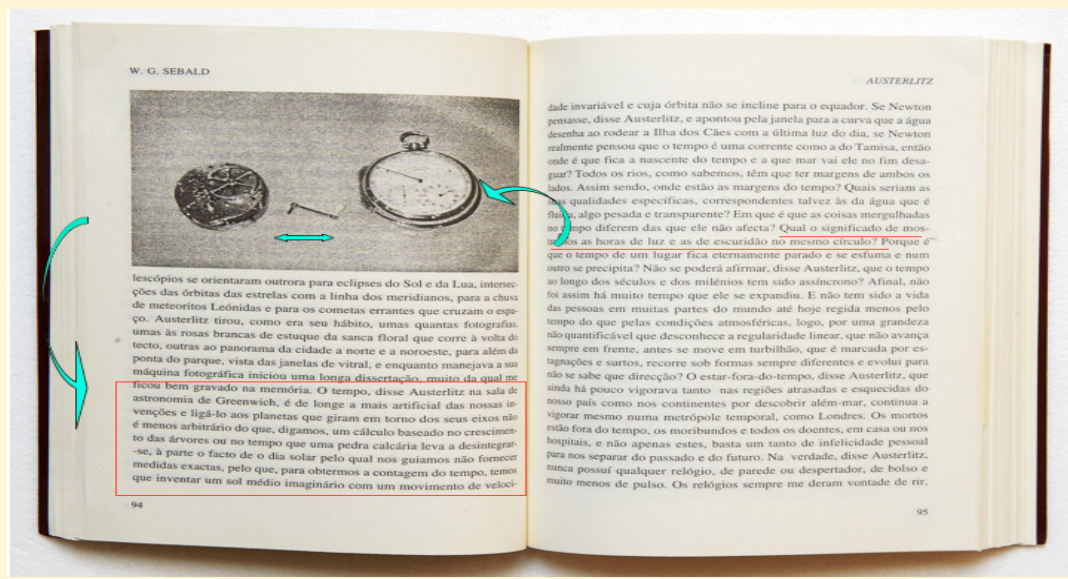

Fig.7B - Páginas 94-95

Neste processo de significação, criado a partir da digressão de Austerlitz, há um impulso em se voltar à fotografia e "re-significar" cada detalhe da imagem. E assim, o cronômetro à esquerda, que se encontra "desnudo", deixa de mostrar apenas a mecânica do aparelho e passa a representar a arbitrariedade do sistema de marcação do tempo. A partir desta inferência também ocorre uma mudança na relação entre os dois aparelhos mostrados lado a lado. Se antes da leitura desta passagem os dois cronômetros eram apenas dois exemplares de um mesmo objeto, depois passam a dialogar não apenas com o texto, mas também entre si, no interior da própria imagem: o eixo de metal entre os dois relógios passa a funcionar como elo simbólico entre passado e presente, entre morte e vida. A morte figurada no cronômetro desnudo e a vida figurada no cronômetro branco, que se encontra pronto para marcar o avançar inexorável dos segundos.

Estas inferências levam-me a concluir que, a fotografia, se relacionando com o texto, perde a fixidez referencial e passa a simbolizar a relação entre passado-presente, entre memória-esquecimento, que se encontram linguisticamente manifestas na divagação de Austerlitz.

Observa-se que, nas versões alemã e brasileira, a imagem vem colocada na mesma posição em relação ao texto (Figs. 5, 6). Po- 
rém o fato de, na versão brasileira (Fig. 6), ser necessário virar a página para se continuar a leitura, provoca a perda do contato visual com a imagem no momento exato onde a digressão poética sobre o tempo adquire a sua maior força. Embora, num primeiro momento, a manutenção da fotografia na mesma posição em relação ao texto, possibilite uma certa coerência com a função conectora das palavras "cronômetros e instrumentos de medição" (Fig. 6), de outro lado restringe o potencial simbólico da fotografia, porque tende a indicar que se trata apenas de uma ilustração das vitrines vistas no museu. Evidentemente esta associação simbólica poderia ser realizada ao se virar a página, mas o elo de tensão poética e a plasticidade da narrativa, que também são componentes do discurso, não se manifestam na sua máxima potencialidade.

$\mathrm{Na}$ versão portuguesa a fotografia é inserida em outro lugar da narrativa e, surpreendentemente, este novo posicionamento acaba por criar um elo de sentido diferente entre a digressão de Austerlitz e a oposição escuro-claro dos dois relógios (Fig. 7 A/B). Mais especificamente a relação é estabelecida com a frase na qual o protagonista indaga porque razão as horas de luz e as horas de escuridão são mostradas na mesma circunferência (p. 95). Apesar da conexão entre os dois regimes de signos ser distinta da versão alemã, esta oferece um diálogo entre o ápice conceitual do texto e a potencialização simbólica da imagem. Tal fato acaba contribuindo para que a imagem se desprenda da sua camada referencial e desempenhe também um papel simbólico no diálogo com o texto.

Através desta consideração pretendo deixar claro que não se trata de engessar o texto e colocá-lo a todo rigor a serviço da imagem ou de seguir fielmente o layout proposto na versão de partida, mas sim de buscar manter os conectores discursivos, que são responsáveis pela vitalidade plástica e simbólica da narrativa.

No segundo exemplo analisado, Sebald utiliza a justaposição como estratégia discursiva. Trata-se de um recurso de linguagem clássico, também muito utilizado na fotografia (p.ex. Cartier-Bresson, Robert Doisneau ou Robert Frank). Sua característica básica consiste em criar, dentro de um único campo visual, uma relação 
de oposições entre dois conceitos ou universos de linguagem distintos, e que por friçção, criam um terceiro sentido (Figs. 8, 10B).

Nas páginas 270 e 271 (Fig. 8) percebe-se dois modos diferentes de lidar com a justaposição. O primeiro ocorre através do jogo de oposições dentro da fotografia mesma e que é acionado pela palavra "ideal" inscrita sobre uma placa pendurada na fachada de um casario arruinado. Na fotografia tem-se uma cena melancólica, de uma rua abandonada, num dia cinza, que mais reflete a antítese e contrasta com a presença do signo linguístico "ideal". Num outro nível da justaposição, a imagem fotográfica se relaciona com a descrição textual da cena de desolamento, que Austerlitz encontra no lugar de uma cidade (Terezín) outrora planejada como "a ideal cidade do sol". Nesta parte da narrativa, o autor está preparando território para descrever exatamente a contradição que havia na ideia de uma cidade que fora forjada pelo sistema nazista para encenar o abrigo de refugiados e de judeus, como se fosse um lugar de bem estar e de proteção, quando na verdade, dissimulava a mutilação e o aniquilamento de prisioneiros de guerra. Fica evidente que a palavra "ideal" atua como um pivô nesta passagem e que dela depende a antítese conceitual criada no interior da imagem e pela relação imagem-texto.

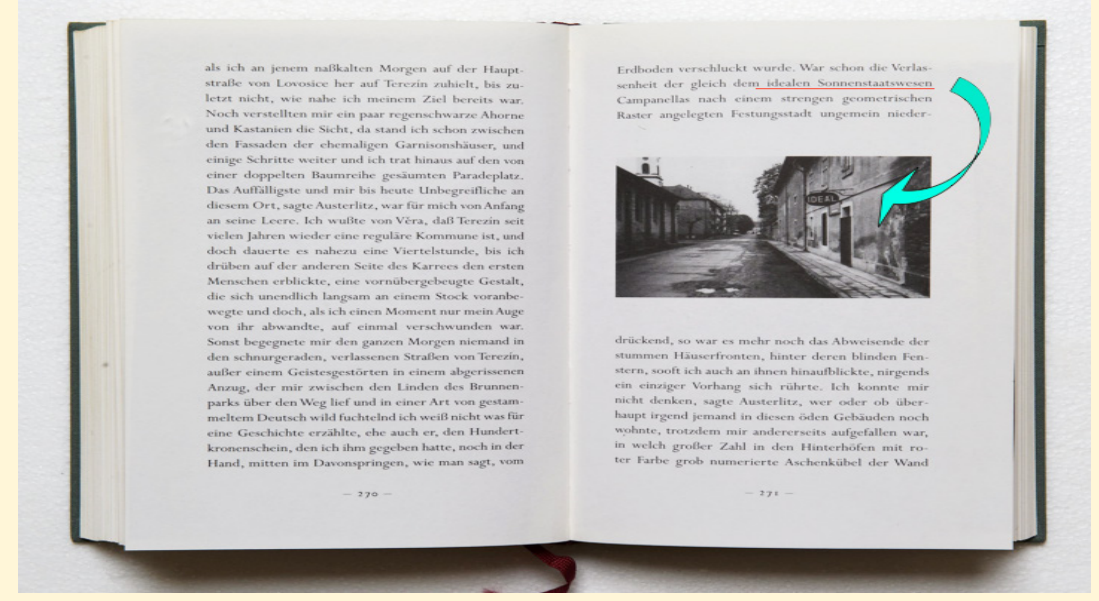

Fig. 8 - Páginas 270-271

Cad. Trad., Florianópolis, $n^{0}$ especial, p. 14-36, jul./dez. 2014 


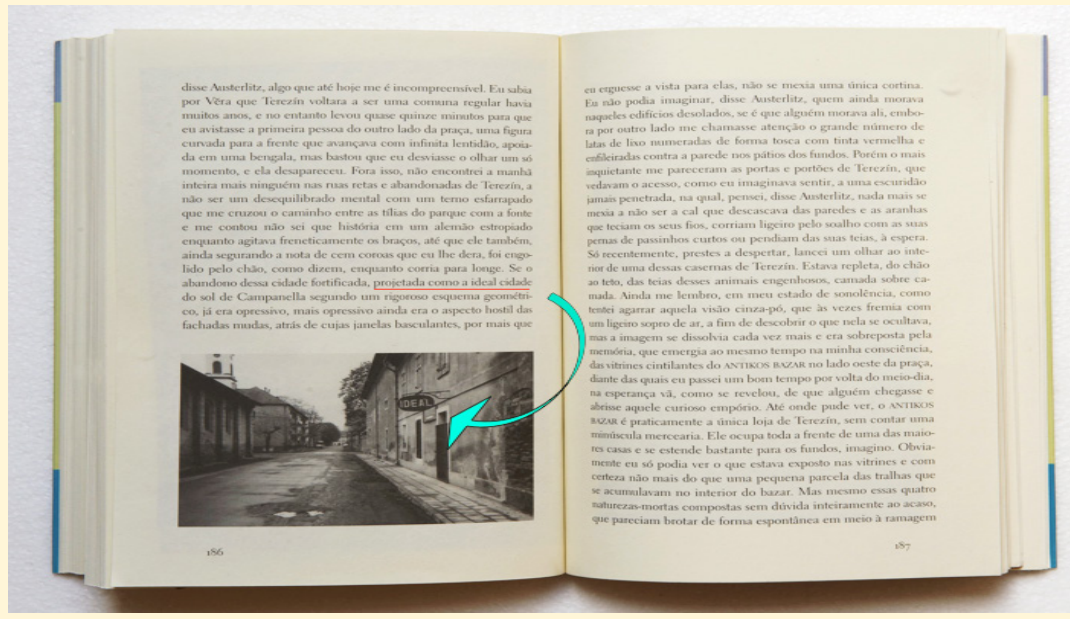

Fig. 9 - Páginas 186-187

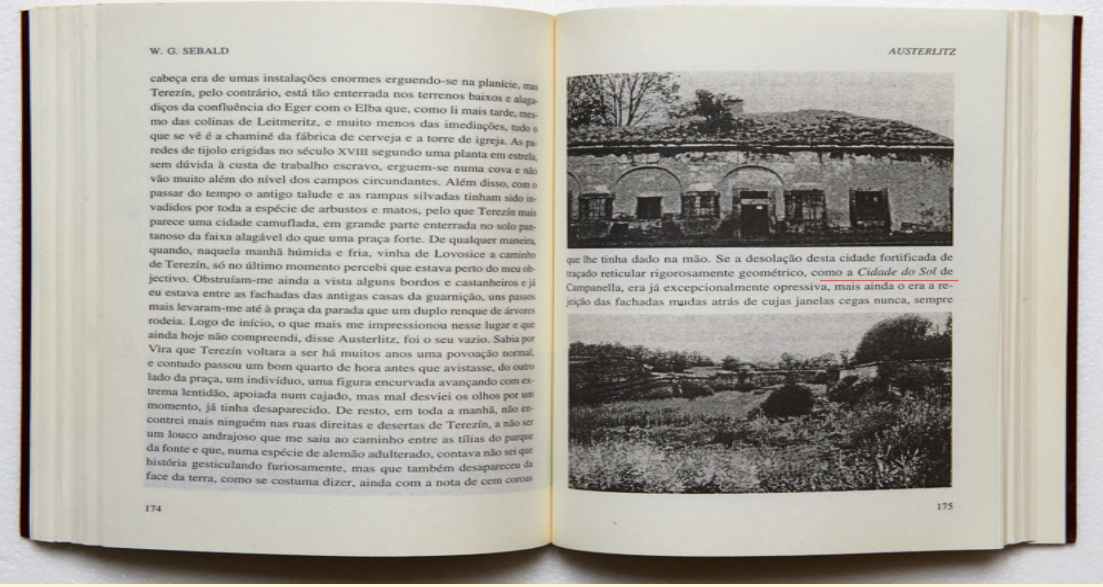

Fig.10A - Páginas174-175 


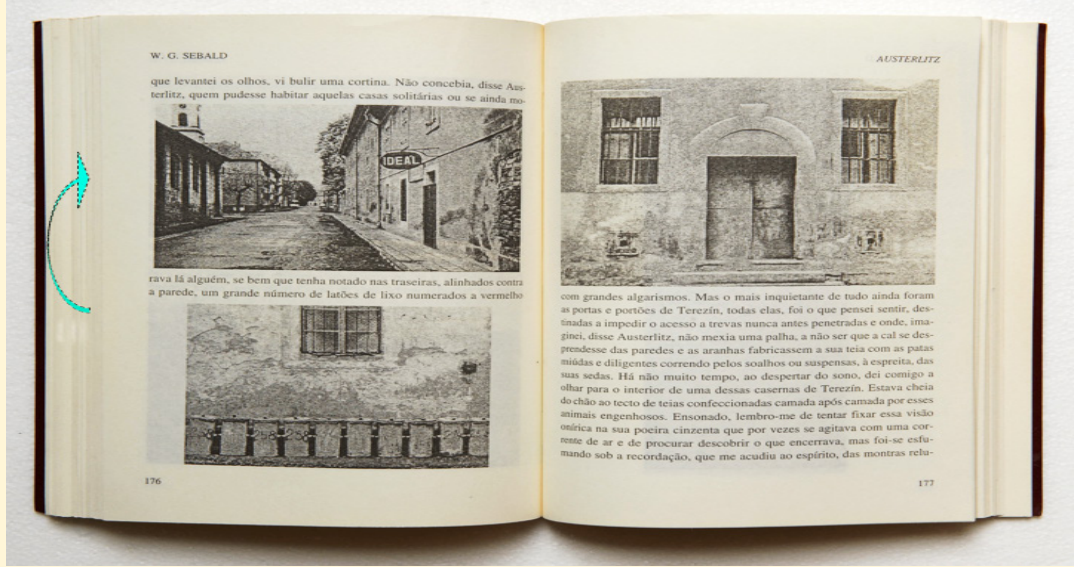

Fig.10B - Páginas 176-177

Na comparação entre as três obras, observa-se que a versão brasileira, apesar de ter modificado a disposição do texto, procurou manter, ao máximo, a proximidade entre a imagem e as sentenças que comunicam a ideia central da página, o que permitiu preservar a função conectora do signo linguístico "ideal” entre o texto e a fotografia (Fig. 9). Na versão portuguesa a situação se torna mais complexa, não apenas porque a imagem, inserida em um outro lugar, é completamente deslocada da descrição central desta passagem, mas, principalmente, por causa da supressão do signo linguístico "ideal" dentro do texto (Figs. 10A/B). A ausência do termo impossibilita que o jogo conceitual entre o texto e a justaposição que vibra na imagem se realize.

Especialmente quando se considera que nas três línguas o signo linguístico "ideal" é representado pelo mesmo significante, não se pode deixar de indagar o porquê da supressão desta palavra na versão portuguesa. Tal fato refletiria apenas uma falha editorial ou revela também um certo descuido ao lidar com aspectos linguísticos e simbólicos que organizam a teia discursiva como um todo?

A estratégia ecfrasística, ricamente utilizada por Sebald, é a característica principal do terceiro exemplo e encontra aqui uma 
forma muito subjetiva de relacionar imagem-texto. (Figs. 11, 13B). Nas páginas 280 e 281 da versão alemã, a fotografia de uma vitrine é apresentada entre duas partes de uma frase que dá início à descrição de uma pequena escultura, encontrada dentre outros objetos antigos e suvenires diversos amontoados nesta vitrine (Fig. 11). Trata-se da figura de um cavaleiro de porcelana, que bravamente resgata uma jovem ameaçada no seu último suspiro de esperança. A descrição detalhada desta escultura é inserida logo abaixo da fotografia, o que torna a interface imagem-texto fundamental para a fruição não apenas dos detalhes da escultura como também para a compreensão de outros aspectos subjetivos que são tratados na análise subsequente.

Esta passagem simboliza o desejo e a busca angustiada do protagonista de ser igualmente salvo por algo ou alguém, que subitamente surgisse do nada para resgatá-lo da sua angústia existencial. A possibilidade de gerar esta inferência (que relaciona a escultura e os objetos da vitrine com o próprio personagem) é descortinada ao leitor apenas posteriormente, quando, descrevendo os objetos esquecidos e amontoados na vitrine, Austerlitz revela perceber refletida na vidraça a sua própria imagem. Neste momento, a narrativa adquire um ápice conceitual que motiva o leitor a buscar de novo a imagem e mirá-la com cuidado à procura deste reflexo, que num primeiro momento é quase imperceptível. Deste modo, o reflexo só adquire valor estético e significado simbólico quando, revelado pelo texto, é de novo percebido na imagem. 


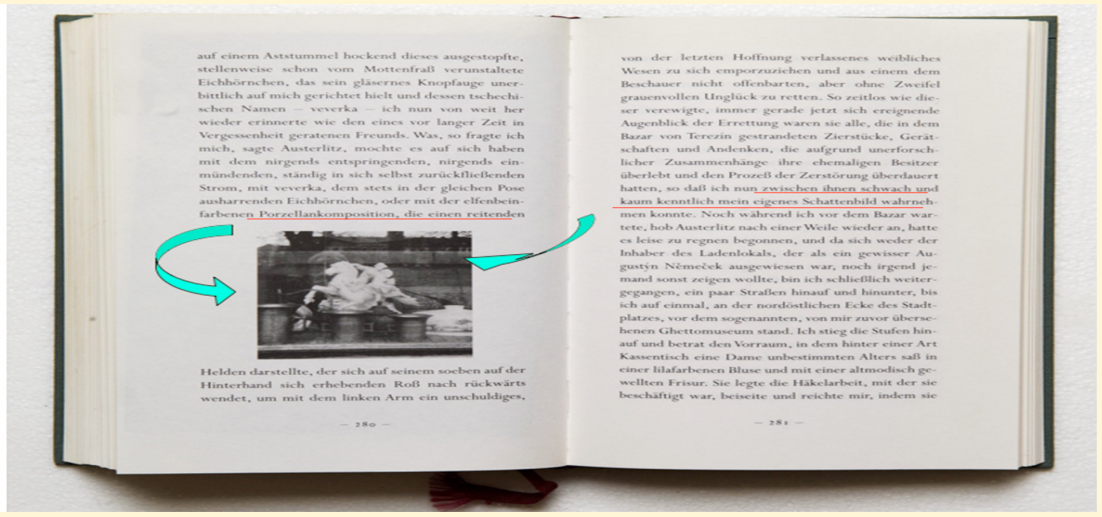

Fig.11- Paginas 280-281

A comparação entre as três versões deixa evidente a disparidade criada por ambas as traduções. Na versão brasileira a fotografia só é apresentada ao final da passagem, depois de completada toda a descrição e digressão em torno da imagem. (Figs. 12A/B) Assim, entendo que, dois aspectos centrais da narrativa são comprometidos: de um lado a função ecfrasística do texto que respira no contato com a figura descrita; e, de outro, a tensão estética e simbólica que é produzida quando o texto induz o leitor a voltar na imagem e reconhecer o reflexo de Austerlitz dentre os "suvenires encalhados", para completar assim o processo de significação e incluir, metaforicamente, a psique do protagonista no rol dos objetos que resistiram à destruição. 


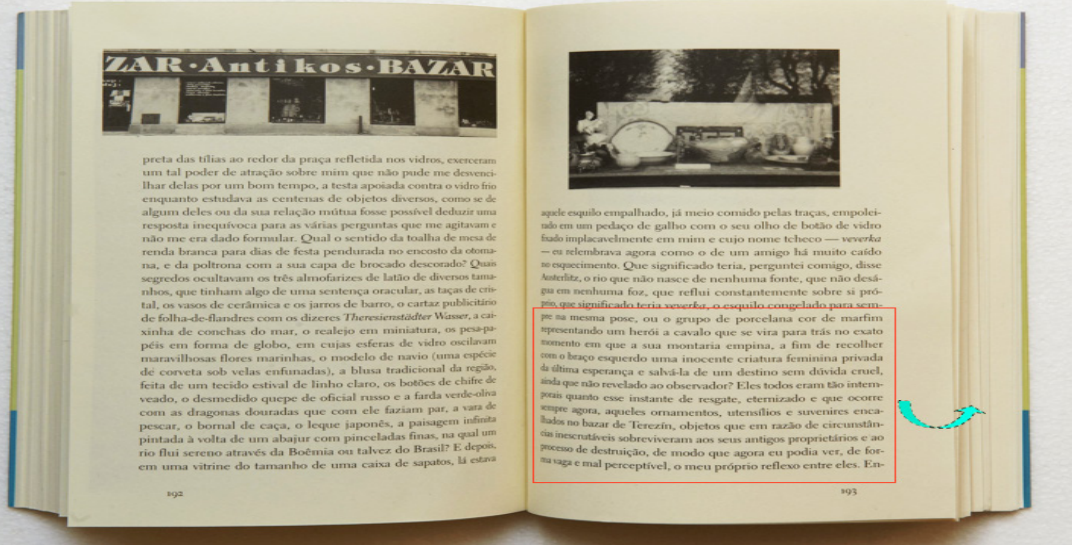

Fig.12 A - Páginas 192-193

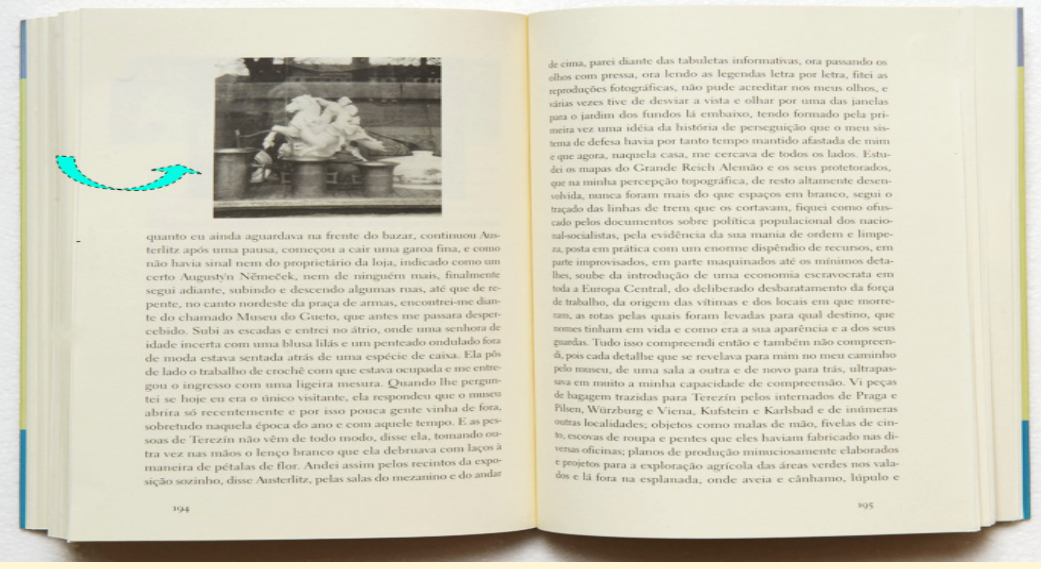

Fig.12B - Páginas 194-195

Cad. Trad., Florianópolis, $n^{0}$ especial, p. 14-36, jul./dez. 2014 


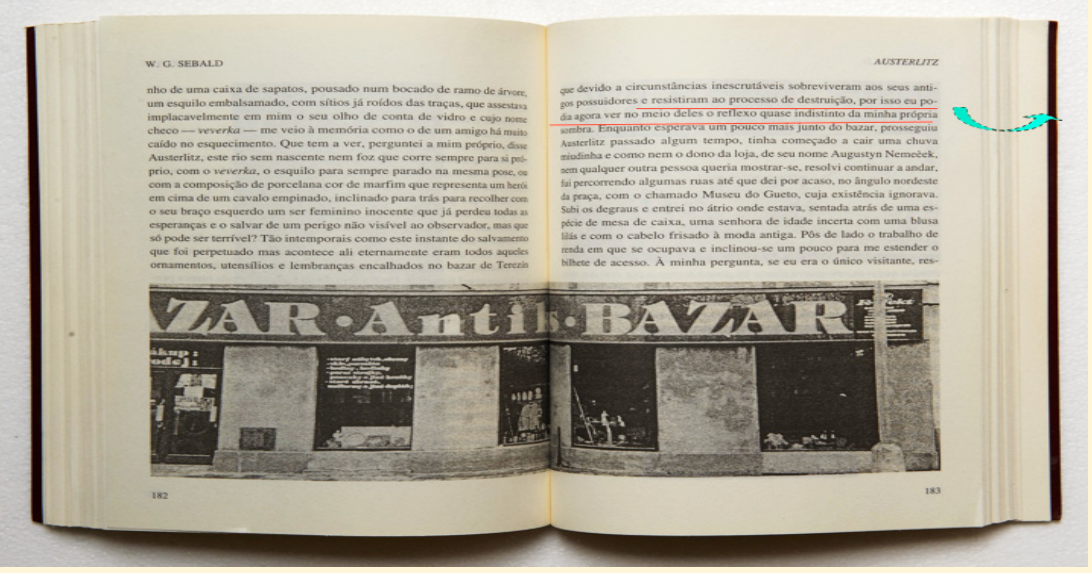

Fig.13 A - Páginas 182-183

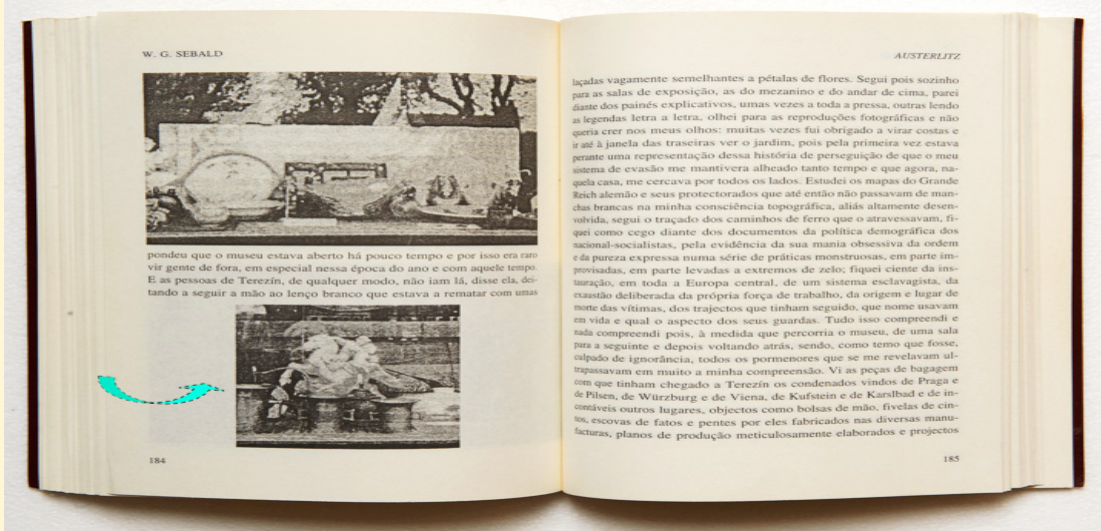

Fig.13B - Páginas 184-185

Ao revelar no texto apenas posteriormente o valor de um detalhe sutil que não seria inicialmente percebido, Sebald cria uma suspensão de sentido e cria um ápice emocional pela surpresa da revelação e associação simbólica. Na nova disposição da versão brasileira, o texto é distribuído de tal forma, que a imagem só é 
acessada na pagina posterior à revelação final. Assim, o auge deste descortinamento, que é sutil, mas fundamental, se desfaz. Em vez de se surpreender com o reflexo e conferir-lhe valor simbólico ao voltar à fotografia, o leitor recebe esta chave de leitura de antemão, o que novamente contribui para transformar a fotografia em uma ilustração "burocrática" do que já foi anteriormente lido.

$\mathrm{Na}$ versão portuguesa a diluição do aspecto emocional é ainda mais evidente. Além da relação espacial entre imagem e texto também ser modificada, outras fotografias são colocadas numa sequência aleatória e se interpõem entre a passagem do texto e a fotografia à qual ela se refere (Figs. 13A/B). Não bastasse isso, percebe-se, ainda, que a baixa qualidade de impressão da imagem, impede, quase que completamente, que o reflexo na vitrine seja percebido. Assim, inserida alhures na página, posterior à descrição da vitrine e à menção do reflexo, e sem oferecer a qualidade visual para ser fruída como parte figural da narrativa, a fotografia passa a atuar como um acessório quase dispensável do discurso. Tal fato destitui a narrativa da relação íntima e desejável entre os dois regimes e que é essencial para a vitalidade emocional e simbólica desta passagem. A construção deste auge simbólico não pode prescindir da proximidade entre os dois regimes de signos e também não pode se efetivar se a imagem é apresentada após a leitura completa desta passagem. Mais uma vez tal fato sugere que a página dupla deva funcionar como um campo único de significação.

\section{Conclusão}

A tradução não é uma atividade unificante que permite esquecer a diferença entre as línguas, mas sim um caminho para se propor a ilusão compartilhada de uma linguagem acessível. Assim deve-se assumir que o gesto tradutor trabalha num campo de indeterminação no qual um texto não pode ser reproduzido palavra por palavra e que tal constitui, paradoxalmente, a tarefa de aceitar que toda tradução sobrevive também da utopia de se criar formas, possibili- 
dades de se transpor a opacidade que encobre a língua (RICOUER, 2005). Nesse sentido, deve-se também reconhecer que em toda tradução haverá sempre uma fresta abissal e intransponível que separa a obra de referência da nova versão criada e, ao mesmo tempo, caracteriza a tradução como gesto criativo e utópico. É desta divisa frágil e complexa entre lidar com a vitalidade criativa e, ao mesmo tempo, manter um elo de contato com a obra de referência, sem se deixar aprisionar pelo mito da fidelidade, que o gesto tradutor se alimenta (LAGES, 2002).

Penso que, quando se trata de uma obra que tem o seu discurso calcado na relação semio-estética, a tradutibilidade depende não apenas de decisões no campo linguístico e semântico, mas também de eleições formais que dizem respeito aos aspectos plásticos da obra tais como formatação e paginação do texto, qualidade de reprodução de uma imagem, etc. Se traduzir é uma forma criativa de buscar transposições entre línguas e linguagens, acredito então que atentar e cuidar dos aspectos estéticos e simbólicos, que envolvem a forma de uma obra, constitui também parte deste desafio.

Se de um lado as análises podem elucidar a vitalidade discursiva que se esconde na interface imagem-texto dentro da obra de Sebald, de outro apontam também quão complexa e utópica é a tarefa tradutora quando esta se confronta não apenas com as distâncias entre as línguas, mas também entre as linguagens. Embora as análises tenham focalizado as diferenças entre as duas traduções, não foi meu intuito dotar a obra alemã de uma aura de pureza e originalidade intocáveis. Não estou a reivindicar que a tradução deveria se prender à literalidade da obra de referência, e sim, propondo olhar para as duas novas versões de língua portuguesa criticamente, para perceber os deslocamentos de sentido que são criados na relação imagem-texto nas duas traduções, expondo assim mais uma faceta que compõe a complexidade da tarefa tradutora (BENJAMIN, 2001).

Se por um lado a similaridade das duas línguas (portuguesa e brasileira) contribui para confirmar mais uma vez que, mesmo se considerado apenas o aspecto linguístico, não há um caminho universal de se lidar com a tradução e que sobrevive nesta impossi- 
bilidade a potencialidade criativa e a riqueza poética do desafio tradutor, por outro, esta similaridade permite também olhar para as três versões de Austerlitz e criar um triângulo comparativo, que situando a obra de partida no vértice de referência, permite focalizar, para além das diferenças linguísticas, as diferenças na forma.

Se a tarefa tradutora que envolve apenas diferenças no campo linguístico já enfrenta dificuldades intransponíveis geradas pela impossibilidade de se contar com uma língua universal, pode-se dizer que estas dificuldades são potencializadas quando se trata de uma obra na qual está em jogo a relação entre regimes de signos distintos. Ao mesmo tempo em que esta potencialização poderia ser vista como um momento de crescimento da obra, no qual esta se engrandece e se completa, também se deve assumir que esta distância impõe certos limites e cuidados, na tentativa de evitar que uma tradução, se afastando tanto da obra de partida, deixe de se justificar como tradução e passe a ser uma outra obra, completamente outra. É deste fio de desejo, frágil, mas também profundo, mantido pela utopia de dizer o mesmo em outra língua, entre criar um elo e ao mesmo tempo ser livre, que pulsa o gesto tradutor.

\section{Notas}

1. Não é interesse, neste artigo, investigar dentro do campo editorial que tipo de estratégia de marketing se esconde por trás das decisões que envolvem a escolha do formato, da mudança de layout, tipos de papel ou técnicas impressão. Saber se elas são motivadas por contenção de custos ou por escolhas estilísticas ou saber quem as delega, não modificaria o caráter da obra publicada. Assim me detenho a focalizar e analisar as obras em si e o modo como nelas o discurso e a narrativa são modificados e não os mecanismos de mercado que envolvem a concepção da edição.

2. O termo foi também utilizado por Floch que desenvolveu, na perspectiva de Greimas, os chamados parâmetros semio-estéticos para buscar compreender os

Cad. Trad., Florianópolis, $n^{0}$ especial, p. 14-36, jul./dez. 2014 
fenômenos semióticos a partir dos aspectos estéticos neles envolvidos (FLOCH, 1995).

3. De certa forma esta ação do tempo reporta aqui metaforicamente à fotografia como recurso de rememoração: ao mesmo tempo em que apreende um instante e nos permite aproximar-nos dele, também nos lembra, sempre, tal como afirma Barthes, que a fotografia é, sempre, portadora de morte (BARTHES, 1984).

4. Dada a relação indicial característica do processo fotográfico, tem-se, claro, como objeto imediato, os relógios que são dados a ver na superfície da fotografia. Este é de modo inegável, o traço de conexão física que a imagem técnica mantém com o seu referente.

\section{Referências}

BAL, Mieke. ReadingRembrandt:BeyondtheWord-ImageOpposition.Cambridge: Cambridge University Press, 1991.

Narratology: introduction to the theory of narrative. Toronto: University of Toronto Press, 1997.

BARTHES, Roland. A câmara clara. Tradução Júlio Castañon Guimarães. Rio de Janeiro: Nova Fronteira, 1984.

BENJAMIN, Walter. A tarefa - renúncia do tradutor. In: HEIDERMANN, Werner (Org.). Clássicos da teoria da tradução. Tradução Susana Kampff Lages. Florianópolis: Núcleo de Tradução (UFSC), 2001. p. 189-215.

FLOCH, Jean-Marie. Identités visuelles. Paris: Universitaires de France, 1995. 
LAGES, Susana Kampff. Walter Benjamin: tradução e melancolia. São Paulo: Edusp, 2002.

. Picture Theory: Essays on Verbal and Visual Representation. Chicago: The University of Chicago, 1995.

MITCHELL, W. J. T. Iconology: image, text, ideology. Chicago: The University of Chicago, 1987.

PATT, Lise. Searching for Sebald: What I Know for Sure. In.: PATT, Lise (Org.). Searching for Sebald: photography after W. G. Sebald. Los Angeles: ICI Press, 2007. p. 16-99.

SEBALD, W. G. Austerlitz. München: Carl Hanser Verlag, 2001.

. Austerlitz. Frankfurt am Main: Fischer Taschenbuch Verlag, 2003.

. Austerlitz. Tradução Telma Costa. Lisboa: Teorema, 2004.

. Austerlitz. Tradução José Marcos Macedo. São Paulo: Companhia das

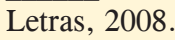

SEARS, John. Photographs, Images, and the Space of Literature in Sebald's Prose. In: PATT, Lise (Org.). Searching for Sebald: photography after W.G. Sebald. Los Angeles: ICI Press, 2007. p.204-25.

RICOEUR, Paul. Sobre a tradução. Lisboa: Livros Cotovia, 2005.

SCHOLZ, Christian. "But the Written Words Is Not a True Document": A Conversation with W.G. Sebald on Literatur and Photography. In.: PATT, Lise (Org.). Searching for Sebald: photography after W.G. Sebald. Los Angeles: ICI Press, 2007. p. 104-9.

Recebido em: 12/02/2014

Aceito em: 23/05/2014 